\title{
SELFIE E SUBJETIVIDADE NA LINGUAGEM DIGITAL
}

\author{
MARALINE APARECIDA SOARES ${ }^{1}$, SILVIA REGINA NUNES ${ }^{2}$
}

Programa de Pós-Graduação em Linguística, Universidade do Estado de Mato Grosso Av. Santos Dumont, Cidade Universitária. 78200-000. Cáceres, MT, Brasil

maralinesoares@hotmail.com , silvianunes@unemat.br

\begin{abstract}
Resumo. Nesta reflexão, filiamo-nos à teoria da Análise de Discurso, sustentada no materialismo histórico, para compreendermos uma manifestação de linguagem, bem como sua relação com o sujeito que a pratica. Referimo-nos ao gesto da selfie e de sua imediata postagem/circulação nas redes sociais, enquanto modo de significação do sujeito contemporâneo no espaço virtual. Propomos pensar os efeitos decorrentes dessa prática, em específico, os modos como se produz o efeito celebridade em relação ao sujeito da selfie e da postagem.
\end{abstract}

Palavras-chave: selfie; subjetividade; discurso.

\begin{abstract}
In this reflection, we join to the Discourse Analysis theory, supported on historical materialism, to understand a demonstration of language, as well as its relation with the subject who practices it. We refer to the gesture of the selfie and its immediate post / circulation in social networks, as a way of meaning of the contemporary subject in the virtual space. We propose to think the resulting effects of this practice, in specific, the ways how the celebrity effect is produced in relation to the subject of the selfie and post.
\end{abstract}

Keywords: selfie; subjectivity; discourse.

\section{Introdução}

Pelo viés da Análise de Discurso, Pêcheux (1995), Orlandi (1996; 2011), Mariani (2007), a presente pesquisa busca compreender os efeitos de sentidos produzidos a partir do gesto da selfie, posto em circulação nas redes sociais, considerando-o como uma forma material de linguagem própria do espaço digital.

Para contextualizar, é importante salientar que o termo selfie é uma expressão de origem inglesa que se define enquanto "a photograph that one has taken of oneself,

\footnotetext{
${ }^{1}$ Mestranda em Linguística pela Unemat.

${ }^{2}$ Doutora em Linguística pela Unicamp. Docente na Universidade do Estado de Mato Grosso, onde atua na Graduação e no Programa de Pós-graduação em Linguística.
} 
typically one taken with a smartphone or webcam and shared via social media" ${ }^{3}$. Nessa definição, já percebemos o caráter tecnológico da prática, sendo produzida por dispositivos móveis, para ser compartilhada nas redes sociais. Expor que a materialidade da selfie é da ordem do digital aponta para um modo específico de significação, que nos direciona a mobilizar alguns conceitos da teoria discursiva, visando compreender o discurso, objeto este construído no entrelugar da Língua, do Sujeito e da História.

Atualmente, com a explosão da tecnologia informatizada, o sujeito passou a se significar no e pelo espaço virtual. Desse modo, há diversos discursos circulando nas redes. Cabe ressaltar que, para Orlandi (1999, p.21), o Discurso é compreendido enquanto "efeito de sentidos entre locutores". Dentre a multiplicidade das manifestações de linguagem que constituem o espaço virtual, trabalhamos com a imagem fotográfica de si em circulação, buscando compreender esse sujeito da selfie, que deseja constantemente se ver-e ser visto. Fotografar a si mesmo e postar essa imagem nas redes sociais tem sido uma prática recorrente nos últimos anos, que envolve pessoas de faixas-etárias diferentes, em diversos lugares no mundo.

\section{Descrição das condições de produção}

Para a Análise do Discurso materialista, não se pode analisar qualquer que seja a manifestação da linguagem fechada sobre si mesma, sem considerar a língua, o sujeito e a história. É fundamentalmente necessário compreendermos o contexto sócio-histórico e ideológico que constitui o sujeito de linguagem e, consequentemente, suas práticas. Nessa direção, trazemos para nossa análise questões que estão diretamente ligadas à produção e à difusão das selfies.

Queremos enfatizar selfie, em seu sentido amplo, como uma prática que nasceu em uma "formação social capitalista, em uma conjuntura sócio-histórica-ideológica determinada pelo avanço tecnológico, pela informatização da sociedade, pela mundialização das relações, entre outras, [...]" (COSTA, 2016, p. 91). Para a Análise do Discurso, tal contexto se inscreve como parte das condições de produção ${ }^{4}$, sendo algo constitutivo na formação dos efeitos de sentidos da linguagem.

Ao mencionarmos o termo linguagem, estamos considerando todos os seus modos de formulação, o verbal, o visual, o sonoro, entre outros. Nesta perspectiva, Orlandi (1995, p. 35) discute que a Análise de Discurso "restitui ao fato de linguagem sua complexidade e sua multiplicidade (aceita a existência de diferentes linguagens) e busca explicitar os caracteres que o definem em sua especificidade, procurando entender o seu funcionamento". A autora defende, ainda, que há uma necessidade no sentido, em sua materialidade, que só significa, por exemplo, na música, ou, na pintura etc.

\footnotetext{
${ }^{3}$ Tradução da definição de selfie: uma fotografia que alguém tira de si mesmo, normalmente através de um smartphone ou webcam para compartilhar nas redes sociais. (cf. OXFORD Dictionaries Online; disponível em https://en.oxforddictionaries.com/definition/selfie. Acesso em: 14 fev. 2016.

${ }^{4}$ Podemos considerar as condições de produção em sentido estrito e temos as circunstâncias da enunciação: é o contexto imediato. E se as considerarmos em sentido amplo, as condições de produção incluem o contexto sócio-histórico, ideológico ( $c f$. ORLANDI, 1999).
} 
Para compreendermos discursivamente essa imagem, neste caso, a fotografia que sustenta a produção da selfie, recorremos aos estudos de Schons:

assim como qualquer imagem tomada como discurso, uma fotografia está necessariamente vinculada ao contexto sócio-histórico e às condições de produção do autor (fotógrafo), que, ao recortar uma imagem, o faz por meio de gestos de interpretação, produzindo e/ou rompendo silêncios, porque mesmo se tratando de descrição e de interpretação de imagens, há uma historicidade de sentidos, levando-se em conta, aí também, o processo de leitura da imagem por parte do sujeito leitor. (SCHONS, 2015, p. 184)

A autora está se referindo ao caso específico da fotografia, em que o fotógrafo apenas realiza o registro, não aparecendo diretamente na imagem produzida. Podemos trazer essa reflexão para o funcionamento da selfie, pois a fotografia é sua forma estruturante. A diferença é que nesta o fotógrafo é aquele que registra e é o fotografado, aparecendo na imagem, a partir dessas duas posições, a do "modelo" e a do produtor da foto.

Nunes (2012, p. 90), ao problematizar a relação entre a palavra e a imagem no funcionamento do infográfico, compreende a imagem em termos de formulação visual. A autora argumenta que não há como tomar a imagem apenas como conteúdo, pois dessa forma esta funcionaria como ilustração, sendo que a relação compósita entre o verbal e o visual, que não separa formas e conteúdo, mostra que o funcionamento da imagem não se reduz ao verbal, mas instaura sentidos próprios nessa composição. Para a autora:

[...] o imaginário de natureza referencial produzido pela formulação visual é determinado pelo efeito ideológico de que a realidade (o mundo) seja transparente, podendo ser representada "fielmente", para isso bastando mostrá-la (numa imagem (foto, desenho...), num vídeo, etc.). Efeito ideológico elementar, como diriam Althusser e Pêcheux (1997b), constituído por uma injunção pragmática à linguagem que coloca em relação direta a palavra e a coisa, e também a possibilidade de controle dos sentidos pelo sujeito. (NUNES, 2012, p. 178)

É a partir dessa concepção acerca da movência dos sentidos, escapando do efeito conteudístico, que temos condições de compreender a imagem fotográfica enquanto linguagem. Existem sentidos que só se realizam em imagens, não reduzindo jamais sua totalidade ao verbal e vice-versa.

No modo como Pêcheux (1980) apresenta a noção de materialidade, propondo um deslocamento na forma de tratamento das "coisas a saber", na qual questiona a análise de conteúdo, podemos considerar a espessura material da selfie, ou seja, a materialidade discursiva desse objeto. Isso porque a selfie marca-se na diferença irredutível daquilo que resulta da relação entre a história (como contradição), a língua (em sua incompletude) e o inconsciente (o impossível). Conforme Orlandi:

Pêcheux afirma que a questão teórica das materialidades discursivas surge daquilo que resulta de heterogeneidade entre a história, a língua e o inconsciente. Em suas palavras: "A questão teórica das materialidades discursivas surge precisamente daquilo que, entre a 
história, a língua e o inconsciente, resulta como heterogeneidade irredutível [...]". Ou seja, do meu ponto de vista, afirmação da posição de entremeio. (ORLANDI, 2016, p. 09)

Assim, a espessura material que sustenta a selfie se constitui na irredutibilidade de seu funcionamento apenas como imagem fotográfica, visto que o gesto de se fotografar se apresenta marcado pelas condições de produção do discurso digital, sendo um gesto que se diferencia da prática do autorretrato, ou, ainda, das práticas da fotografia nas condições de produção de sua invenção, uma vez que os instrumentos tecnológicos disponíveis (lápis, pincel, daguerreotipo, câmera, smarthphone), bem como a circulação dessa "imagem de si", foram e são reguladas, por exemplo, por aparatos tecnológicos diferentes, em diferentes condições de produção. Mais ainda, os efeitos produzidos a partir da compreensão dessas práticas (autorretrato - fotografia - selfie) também engendram efeitos diferentes, na medida em que convocam interpretações (im)possíveis, de acordo com sua peculiaridade. Um autorretrato exposto numa galeria de arte, num museu ou circulando nas telas de uma página da internet, não produz o mesmo sentido que uma selfie postada no Facebook, cuja expectativa busca seu reconhecimento na forma de curtidas e compartilhamentos. Uma fotografia $3 \times 4$ que compõe um documento de identidade não produz o mesmo efeito de sentido que uma selfie. Isso é o que marca a irredutível heterogeneidade dos objetos paradoxais, eles têm a propriedade de parecerem ao mesmo tempo idênticos e diferentes.

A atual conjuntura sócio-histórica, sendo esta capitalista, é regida pelas ideologias de Mercado, que tem como discurso fundante o "Sucesso" (PAYER, 2005). Para Debord (1992), temos uma sociedade que prefere a imagem à coisa, a cópia ao original, a representação à realidade, a aparência ao ser. Podemos ver todas estas questões funcionando na e pela linguagem. Nas palavras de Debord,

o fluxo de imagens domina tudo, e é igualmente qualquer outro que governa a seu gosto este resumo simplificado do mundo sensível que escolhe aonde irá esta corrente, e também o ritmo daquilo que deverá manifestar-se nela, como perpétua surpresa arbitrária, não deixando nenhum tempo para a reflexão, e em absoluto, independentemente do que o espectador possa compreender ou pensar. (DEBORD, 1992, p. 29-30)

Dando continuidade ao que diz respeito às condições de produção, faz-se necessário descrevê-las, também, em sentido estrito, apresentando qual será nosso material de análise: a selfie publicada na página da Revista Glamour e reduplicada pela página Nana Rude e pelas redes sociais Facebook e Instagram.

Para compreendermos o funcionamento do gesto da selfie e de sua imediata postagem/circulação nas redes sociais, trazemos o modo como um desses gestos circulou e se reduplicou, a partir de uma revista digital. Buscamos, a partir das condições de produção da publicação da revista, compreender também os efeitos ideológicos que sustentam tal publicação, ao dar visibilidade à selfie nessa reportagem, sob o título: "Isaac Deyson, o "coveiro magia" que está arrasando na web".

A referida revista surgiu, inicialmente, na versão impressa, nos Estados Unidos, em 1939, momento em que era intitulada Glamour off Hollywood. Atualmente, alcançou 
diversos países, sendo lançada no Brasil, em abril de 2012, pela Editora Globo. Suas edições são mensais e funcionam por assinatura, tanto na versão impressa, quanto na digital. Faz-se presente também nas redes sociais (Facebook, Instagram, Twiter, entre outros). Tem como público-alvo as mulheres e suas publicações estão voltadas para Moda, Beleza e Celebridade.

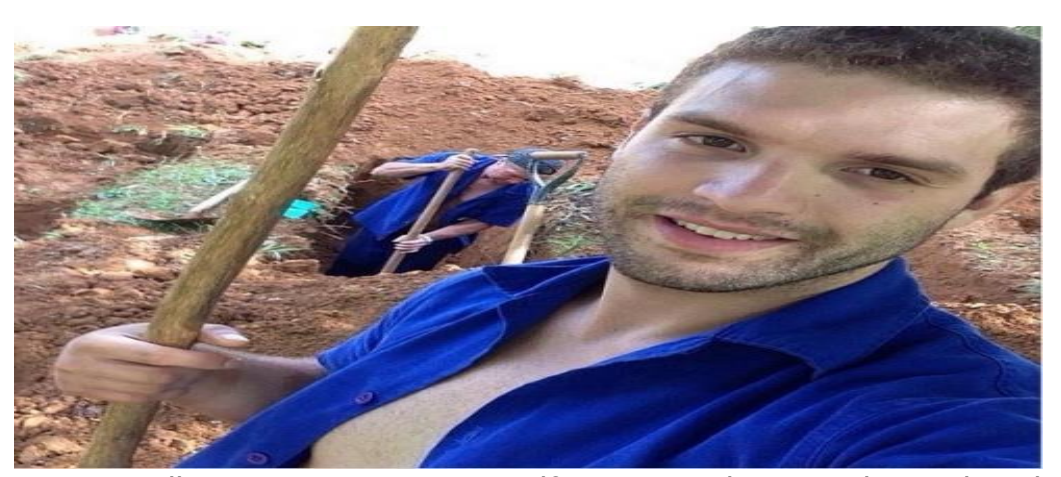

Figura 1. Disponível em http://revistaglamour.globo.com/Celebridades/Hot-news/noticia/2014/03/isaacdeyson-o-coveiro-magia-que-esta-arrasando-na-web.html. Acesso em: 10 abr. 2016.

No dia 30 de março de 2014, disponível no formato digital, e na opção Celebridade (disponibilizada no menu), sob o tópico denominado HOT NEWS, foi publicada a entrevista, acompanhada da selfie que recortamos, com a seguinte legenda: "Isaac Deyson, o 'coveiro magya' que está arrasando na web".

Desse modo, conforme as informações disponibilizadas na entrevista publicada, a selfie diz respeito a um paulistano com idade de 22 anos, estudante de Engenharia Civil, que trabalhava em uma multinacional, mas que, devido à uma mudança na diretoria da empresa e à realização de um corte no quadro de funcionários, perdeu o emprego. Antes que ficasse desempregado, sua mãe soube de um concurso municipal com vagas para a função de coveiro e logo sugeriu que se inscrevesse, argumentando que emprego não estava fácil e que um concurso público seria mais interessante pela estabilidade.

A princípio Isaac diz ter recusado a ideia, afirmando que nem mesmo nos funerais familiares tinha coragem de ver o falecido. A mãe do rapaz fez a inscrição dele e deixou para avisá-lo dois dias antes da prova. Por fim, ele acabou realizando a prova, e garantiu sua vaga no concurso. Como se encontrava desempregado, não hesitou mais em aceitar a nova função.

O que nos chama a atenção é o relato desse rapaz, publicado na reportagem da revista, dizendo ter postado essa selfie na rede social Facebook, estando em seu atual ambiente de trabalho, o cemitério municipal de São Paulo e agradecendo aos compartilhamentos, afirmando terem mudado seu mundo. Vemos na imagem da Figura 1, conforme apresentada pela revista, em segundo plano, covas abertas, inclusive mostrando um colega de profissão trabalhando em uma delas. Isaac está vestido com o uniforme de coveiro e segurando, na mão direita, a ferramenta de trabalho, uma pá.

Foi essa selfie, nessas condições de produção mencionadas pela revista, que despertou a atenção dos organizadores de uma página no Facebook e também no 
Instagram, chamada Nana Rude ${ }^{5}$. Desse modo, a equipe compartilhou essa selfie do Isaac, chamando a atenção dos internautas para o "Coveiro Magya que eles haviam encontrado nas redes sociais". Poucos minutos após o compartilhamento efetuado pela página Nana Rude, houve mais de 40 mil curtidas.

Desde então, conforme pesquisas realizadas na internet, Isaac Deyson, agora denominado pelas redes sociais como Coveiro Magya, passou a ser procurado pela mídia televisiva, incluindo a visita da equipe do TV Fama ao cemitério para entrevistá-lo. $\mathrm{O}$ rapaz também foi convidado para estar no programa Domingão do Faustão, Balanço Geral, Game do Leão etc. Como resultado dessa repercurssão de sua selfie, fechou um contrato para fazer um ensaio sensual, e afirma também ter recebido convites para campanhas publicitárias e para presença VIP em eventos. Simultâneo a esses acontecimentos, a Revista Glamour o chamou para fazer uma entrevista, uma revista que, como já mencionado, trabalha com moda, beleza e Celebridade.

\section{Princípios teóricos e procedimentos analíticos}

Com base nas condições de produção apontadas, focamos nossa análise no modo como a formulação e circulação da entrevista da Revista Glamour pode produzir sentidos acerca de uma posição-sujeito constituída na relação com o discurso eletrônico, mas para isso é importante destacarmos como a Análise do Discurso, uma teoria do entremeio (Materialismo Histórico, Linguística e Psicanálise), pensa a constituição desse sujeito. Sustentamo-nos na relação entre a teoria discursiva e a Psicanálise para compreendermos essa constituição, pois, conforme Henry (1992, p. 187), "a psicanálise define a linguagem como condição do inconsciente e o sujeito como efeito da linguagem enquanto realização do simbólico".

Recorremos, dessa maneira, às palavras de Magalhães e Mariani, que trabalham os processos de subjetivação e identificação na relação com a ideologia e o inconsciente.

Para a Análise do Discurso, o sujeito é constituído pelo esquecimento daquilo que o determina, ou seja, não se dá conta de sua constituição por um processo do significante no funcionamento da linguagem na interpelação ideológica e na identificação imaginária a determinados sentidos. Desse ponto de vista, falar do sujeito é falar de efeito de linguagem; sujeito enquanto um ser de linguagem que foi falado antes de falar, que traz marcas do discurso do Outro, o que implica considerar que o sujeito não é origem do dizer nem controla tudo o que diz. (MAGALHÃES; MARIANI, 2007, p. 402-403)

Assim, para a autora, o indivíduo empírico passa a ser sujeito de linguagem numa relação com o grande Outro, mediada por pequenos outros que nos transmitem os significantes. Desse modo, o indivíduo já nasce recebendo esses significantes que o vão constituindo, ou seja, nós somos sempre o atravessamento desse grande Outro, sendo esse um processo de formação do inconsciente. Em se tratando da linguagem em seu caráter

\footnotetext{
${ }^{5}$ Essa página, citada na entrevista da Revista Glamour, foi criada em 2013 e apresenta um caráter humorístico ao trazer as informações sobre os famosos, contando, também, com uma seção destinada ao que designam como BOYSDANANA.
} 
incompleto, não conseguimos dizer tudo, há uma falta que nos constitui. Conforme nos explicam Magalhães e Mariani:

Como vimos, a transmissão do significante vem do outro e nessa transmissão tanto se efetiva a possibilidade de tornar-se sujeito... falante quanto faltante. Se podemos supor que a transmissão da falta se dá pelo contato com os pequenos outros, não podemos descartar a sociedade, a cultura e a história, enfim, o meio no qual o sujeito se insere. Esse meio sócio-histórico produz efeitos no modo como a transmissão se realiza. (MAGALHÃES; MARIANI, 2007, p. 405)

Desse modo, esse sujeito de linguagem, movido pela falta que o constitui, esse vazio entre um significante e outro - sem se dar conta que essa incompletude é constitutiva da linguagem e, consequentemente, do sujeito - estará constantemente buscando se completar nas mais variadas formas de manifestação da linguagem.

Podemos pensar esse processo de subjetivação no gesto da selfie, em que o sujeito ao buscar saber de si se fotografa, movido por essa emergência de se conhecer e de se mostrar. É um gesto de dizer para si e para os outros sobre quem ele é (ou deseja ser). Mas esse sujeito não é sempre o mesmo. Então, uma imagem fotográfica, formulada enquanto selfie, que ele reproduz de si, pode não corresponder à sua imaginária completude. Nessa posição-sujeito que vai repetindo o gesto desse auto fotografar-se, compreendemos um funcionamento que mostra uma paráfrase ${ }^{6}$ de si. E, pensando esse gesto no espaço virtual, lugar da memória metálica, o sentido se dá na quantidade das selfies postas em circulação nas redes sociais.

Memória metálica é um conceito da Análise de Discurso, desenvolvido por Orlandi (1996), para compreender o funcionamento da linguagem na internet. Para nossa discussão, traremos a definição deste tal como está posta na enciclopédia discursiva da cidade - ENDICI - disponibilizada em versão eletrônica, desde o ano 2001. O verbete apresentado foi elaborado por Cristiane Dias:

na memória metálica, a significação se dá no nível da circulação. Tomando como exemplo o Twitter ou o Facebook, quanto mais atualizações um sujeito fizer em seu perfil, mais visibilidade terá porque aumentará a circulação. Vemos que nesse caso, o ponto de partida para a construção dos sentidos não é a filiação do sujeito a uma rede de constituição, mas a uma atualização e circulação. "Repetição e quantidade, em sua forma binômica" (Orlandi, 2010). O já-dito armazenado que retorna sob a forma da atualização de dados num ultradiscurso e não da formulação do interdiscurso num intradiscurso. (http://www.labeurb.unicamp.br/endici/index.php?r=verbete/view\&id=119)

Nesse sentido, o sujeito que produz a selfie procura se reconhecer na sua própria imagem, e, se reconhecendo, a coloca em circulação por meio da postagem. O sujeito não produz apenas uma selfie, esse gesto é marcado por repetições até se chegar, imaginariamente, numa que ele considere ideal. Nesse movimento marcado pela busca de

\footnotetext{
${ }^{6}$ Os processos parafrásticos são aqueles pelos quais em todo dizer há sempre algo que se mantém, isto é, o dizível, a memória. [...] A paráfrase representa assim o retorno aos mesmos espaços do dizer. Produzem-se diferentes formulações do mesmo dizer sedimentado. A paráfrase está do lado da estabilização ( $c f$. ORLANDI, 1999).
} 
se reconhecer, ele vai se constituindo também pelo funcionamento da memória metálica (no espaço virtual) por meio da repetição, ou seja, na relação com o outro sujeito internauta, que ao olhar tais imagens, atribui sentidos para essa posição-sujeito na rede. Daí a ideia de compreendermos a selfie enquanto materialidade discursiva, pois produz efeitos e torna visível o processo de subjetivação que constitui esse sujeito; é a imagem fotográfica de um corpo, enquanto texto a ser lido. Esse acontecimento nos remete à noção de narcisismo desenvolvida pela Psicanálise, a partir do mito de Narciso. Vejamos a Estória de Narciso e Eco.

Conta-se que, certa vez, Narciso passeava nos bosques. Perto dali, a ninfa ECO, que era uma tagarela incorrigível, acompanhava-o, admirando sua beleza, mas sem deixar que a notasse. Eco, em virtude de sua tagarelice, foi punida por Hera, esposa de Zeus, para que sempre repetisse os últimos sons que ouvisse (por isso, na física, chamamos de eco a reverberação do som). Por sua vez, Narciso, suspeitando de que estava sendo seguido, perguntou: "quem está aí?". E ouviu: “Alguém aí?" Então, ele gritou novamente: "Por que foges de mim?". E ouviu "foges de mim". Até dizer "Juntemo-nos aqui" e ter como resposta "juntemo-nos aqui". Toda essa repetição acabou deixando Narciso angustiado por desejar amar algo que não poderia ver. Dessa forma, Narciso entristeceu-se e foi à beira de um lago, onde, de modo surpreendente, deparou-se com sua imagem nos reflexos da água. Como nunca antes havia se olhado (pois sua mãe foi recomendada a não permitir que isso ocorresse), enamorou-se perdidamente, acreditando ser a pessoa com quem estava "dialogando". Por isso, tentou buscar incessantemente o seu reflexo, imergindo nas águas nesse intento, mas acabou morrendo afogado. A ninfa Eco sentiu-se culpada e transformou-se em um rochedo, vivendo a emitir os últimos sons que ouve. Do fundo da lagoa, surgiu a flor que recebeu o nome de Narciso e tem as suas características.

(http://brasilescola.uol.com.br/mitologia/estoria-narciso-eco.htm)

A partir das palavras do psicanalista Alexandre Simões, conforme apresentadas em seu vídeo, disponível no canal do YouTube, no mês de maio de 2014, intitulado: "O que é Narcisismo?”, podemos dizer que, para a Psicanálise, a noção de narcisismo compreende a relação do sujeito com a sua imagem (enquanto um reflexo), a identificação e o investimento. Associa, portanto, a relação entre os personagens do mito Narciso e Eco às pessoas que se relacionam com os outros buscando a si próprios, o seu eco. $\mathrm{O}$ que reverbera no funcionamento da selfie, que circula num espaço de relações com os outros, as redes sociais.

Sobre a relação do sujeito com a imagem de si, na noção do narcisismo, está na forma de se ver e de se apresentar, ou seja, no modo de se fazer ver pelo outro numa relação de dependência, buscando, imaginariamente, a expectativa desse outro. E quanto ao processo identificatório, a relação está no sentido de se apresentar na imagem fotográfica e também identificar-se com ela. Já o investimento está para o que essa imagem e identificação exigem de energia do sujeito para sustentar essa selfie. Esse modo de pensar o sujeito narcisista, trazido pela Psicanálise, faz relação com o gesto de produção e postagem da selfie, compreendida enquanto algo da subjetividade. Como explicam Magalhães e Mariani. 
Em resumo, a subjetividade - no que ela se mostra, no que se esconde, no que é repetição ou equívoco, no que se marca como diferença, no que se inscreve enquanto homogeneidade - resulta do acontecimento da linguagem no sujeito. Um acontecimento que tanto possibilita a singularização da diferença, quanto a regulação do sujeito relativamente a uma universal adaptação do sujeito à ordem cultural $\mathrm{e}$ social, através do mesmo simbólico que o constituiu. (MAGALHÃES; MARIANI, 2007, p. 398)

O ritual de funcionamento da selfie, que compreende o gesto de se fotografar, postar nas redes sociais para a circulação e angariar reconhecimento através das reações (curtir, amar, odiar, etc., comentários e compartilhamentos) produz essa outra posiçãosujeito. Essa posição-sujeito que, pelo gesto da selfie, marca sua singularidade relacionada à profissão de coveiro. E, por meio dela se instaura a possibilidade de reconhecimento, de si e do outro, através da imagem fotográfica, em segundo plano, de um outro lugar, o cemitério.

Podemos compreender, então, a materialidade discursiva da selfie, visto que ela instaura um ponto de diferença para o sujeito se significar, pois produz efeitos de sentidos, e "não há sentido sem interpretação". Além disso, diante de qualquer objeto simbólico o homem é levado a interpretar" (ORLANDI, 1999, p. 45).

A circulação da selfie, que estamos analisando, se mostra a partir dos milhares de compartilhamentos e curtidas produzidos, o que significa que pode ter causado estranhamento-identificação. A página chamada Nana Rude, localizada no Facebook e no Instagram compartilhou a selfie, chamando a atenção dos internautas para "O coveiro que eles haviam encontrado nas redes sociais", interpretando-a como algo surpreendente, como um efeito que quebra a ideia posta sobre o padrão de beleza de um coveiro.

Tanto a página Nana Rude quanto a Revista Glamour são espaços voltados à circulação de imagens fotográficas de celebridades, pessoas conhecidas no Brasil e até mesmo em outros países. A selfie foi publicada no espaço das celebridades, ou seja, foi a partir do olhar do outro, num gesto interpretativo para a selfie postada/compartilhada, que lhe foi conferido o status de celebridade. Vale ressaltar que a entrevista menciona que a repercussão da selfie acarretou diferentes oportunidades de trabalho ao "Boy Magya", mesmo que ele não pretenda deixar o emprego de coveiro, argumentando sobre a importância da estabilidade, mas que se organiza para as novas propostas sem ter que se ausentar do emprego. Contudo, ao ocupar essa posição de dizer, compreendemos que ela se sustenta na aprovação dada pelo olhar do outro, registrada nas redes sociais que lhe conferiu o status de celebridade de forma instantânea.

\section{Considerações finais}

Mediante ao que se apresenta na análise, consideramos que não há neutralidade na linguagem, e, sim, opacidade e que os gestos de interpretação de si mesmo, na relação com a expectativa do outro, são atravessados por uma vasta rede de efeitos de sentidos de reconhecimento, identificação, aceitação, surpresa etc. Ao sair do campo da evidência, temos acesso ao modo como a linguagem, a ideologia e o inconsciente estão sustentando 
o ritual da selfie, no que diz respeito à sua produção e circulação, envolvendo tanto aquele que produz, quanto o que noticia, curte, comenta e compartilha.

Nessa conjuntura, a selfie pode ser compreendida como um gesto de interpretação que o próprio sujeito realiza de si, afetado por formações imaginárias que estão em funcionamento nas redes sociais. Desse modo, quando estamos diante de uma selfie imaginamos que seja uma imagem fotográfica que representa a realidade, porém não podemos tomá-la nessa transparência, pois o que temos nela são versões de "eus" que se simbolizam nessa imagem fotográfica.

O gesto da selfie se constitui na relação com essa posição-sujeito que seleciona de antemão o que mostrar de si, a fim de assegurar o modo como se vê e é visto. Contudo, ao colocá-la em circulação, por meio das postagens nas redes sociais, essa questão se perde, não sendo possível controlar os efeitos de sentidos, pois o processo de interpretação está relacionado à formação sócio-histórica e ideológica que sustentam esses efeitos. Procuramos, portanto, dar visibilidade, através do material que recortamos para análise, a algumas possíveis interpretações que se deram em forma de publicação e compartilhamento da selfie por parte das páginas Revista Glamour e Nana Rude.

Por ora, estas são as considerações de uma pesquisa que se encontra em desenvolvimento.

\section{Referências}

COSTA, G.C. da. A palavra do ano é uma imagem. Fragmentum, Santa Maria, Programa de Pós-graduação em Letras, UFMS, n. 48, 89-103, jul. - dez. 2016.

DEBORD, G. A sociedade do espetáculo. Editoração, Tradução do prefácio e versão para eBook: eBooksBrasil.com, 1992.

MAGALHÃES, B.; MARIANI, B. Processos de subjetivação e identificação: ideologia e inconsciente. Linguagem em (Dis)curso, Palhoça, SC, v. 10, n. 2, 391-408, maio/ago. 2010 .

NUNES, S.R. A geometrização do dizer no discurso do infográfico. Tese. Doutorado em Linguística, UNICAMP, Campinas, SP, 2012.

Metáfora e espetáculo no discurso de divulgação científica da mídia. Dissertação. Mestrado em Letras, UEM, Maringá, 2005.

ORLANDI, E.P. Nota introdutória à tradução brasileira de Materialidades Discursivas. Em: PÊCHEUX, M. et al. Materialidades Discursivas. Campinas: Ed. da Unicamp, 2016.

Língua, comunidade e relações sociais no espaço digital. Em: DIAS, C. Eurbano: sentidos do espaço urbano/digital [on-line], 2011. Disponível em 
http://www.labeurb.unicamp.br/livroEurbano/ Laboratório de Estudos Urbanos. Acesso em: 10 jul. 2016.

$\frac{1}{1999 .}$. Análise do discurso: princípios e procedimentos - São Paulo. 8 ed. Pontes, 1996.

Interpretação; autoria, leitura e efeitos do trabalho simbólico. Petrópolis: Vozes,

Efeitos do verbal sobre o não-verbal. Rua, Campinas, 1, 35-47, 1995.

PAUL, H. A ferramenta imperfeita: língua, sujeito e discurso. Trad. Bras. Campinas, SP: Editora da UNICAMP, 1992.

PAYER, M.O. Linguagem e sociedade contemporânea - sujeito, mídia e mercado. Rua, Campinas, 11, p. 9-25, 2005.

PÊCHEUX, M. Semântica e discurso: uma crítica à afirmação do óbvio. Campinas: Ed. da Unicamp, 1988.

O discurso: estrutura ou acontecimento. Campinas: Pontes, 1990.

SCHONS, C.R. Sociedade, corpo e relação subjetiva. Acta Scientiarum [Language and Culture], Maringá, v. 37, n. 2, 181-188, apr.- jun. 2015.

\section{Lista de canais do YouTube}

Simões, Alexandre. O que é o Narcisismo? Disponível em:

https://www.youtube.com/watch?v=0NZnqrkAjh8. Acesso em: 1 jul. 2016.

O estádio do espelho. Disponível em:

https://www.youtube.com/watch?v=jXIbm4agHgM. Acesso em: 5 jul. 2016.

\section{Links acessados para pesquisa}

Mito de Narciso. Disponível em http://brasilescola.uol.com.br/mitologia/estoria-narcisoeco.htm. Acesso em: 2 jul. 2016.

DIAS, Cristiane. Memória Metálica. Disponível em http://www.labeurb.unicamp.br/endici/index.php? $\mathrm{r}=$ verbete/view\&id=119. Acesso em: 5 jul. 2016.

Reportagem realizada pela Revista Glamour sobre o Coveiro Magia. Disponível em http://revistaglamour.globo.com/Celebridades/Hot-news/noticia/2014/03/isaac-deysono-coveiro-magia-que-esta-arrasando-na-web.html. Acesso em: 01 jul. 2016. 
Artigo recebido em: julho de 2017.

Aprovado e revisado em: outubro de 2017.

Publicado em: novembro de 2017.

\section{Para citar este texto:}

SOARES, Maraline Aparecida; NUNES, Silvia Regina. Selfie e subjetividade na linguagem digital. Entremeios [Revista de Estudos do Discurso, on-line, www.entremeios.inf.br], Seção Temática [Linguagem e Tecnologia], Programa de PósGraduação em Ciências da Linguagem (PPGCL), Universidade do Vale do Sapucaí (UNIVÁS), Pouso Alegre (MG), vol. 15, p. 267-278, jul. - dez. 2017.

DOI: http://dx.doi.org/10.20337/ISSN2179-3514revistaENTREMEIOSvol15pagina267a278 